\title{
Fundoplication in 160 Children Under 2 Years of Age
}

\author{
By Nina L. Kazerooni, Joan VanCamp, Ronald B. Hirschl, Robert A. Drongowski, and Arnold G. Coran \\ Ann Arbor, Michigan
}

\begin{abstract}
- The natural history of fundoplication in young children with gastroesophageal reflux (GER) had not been analyzed previously. The authors reviewed the charts of 160 children who underwent gastric fundoplication (GF) before the age of 2 years (mean age [ $\pm S D$ ], $9 \pm 7$ months; range, 1 week to 2 years), from 1974 to 1992. Reflux was documented by upper gastrointestinal series in 124 patients, by 24 -hour pH probe monitor in 98 patients, and by both in 68 patients. Clinical indications for GF included failure to thrive (FTT) in $68 \%$, emesis (Ems) in $58 \%$, and aspiration pneumonia (Asp) in $53 \%$. Neurological impairment (NI) was present in $47 \%$ of all patients, and $13 \%$ had esophageal atresia (EA). The type of GF used was a Nissen fundoplication in $79 \%$ and an anterior fundoplication (AF) in $21 \%$. Of the 160 patients, 24 (15\%) died of unrelated causes. Of the remaining 136, follow-up of at least 2 years was obtained for 96 (mean follow-up period, $5.3 \pm 3.0$ years; range, 2 to 15 years). Clinical resolution of symptoms/findings after GF occurred in $87 \%$ of children with FTT, 92\% with Ems, $70 \%$ with Asp, and $71 \%$ overall. A second fundoplication was required for 15 children $(16 \%)$ because of documented recurrent reflux. The type of GF, the age of the patient, and the presence of EA or NI did not significantly affect the success of GF. This experience demonstrates that (1) in young children there is no inordinate increase in recurrence after GF, (2) GF (AF or Nissen) is an effective means of treating GER in children under 2 years of age, even those with EA or NI.

Copyright $\odot 1994$ by W.B. Saunders Company
\end{abstract}

INDEX WORDS: Gastroesophageal reflux; fundoplication, infants.

$\mathbf{M}$ ANY STUDIES substantiate the efficacy of gastric fundoplication (GF) in alleviating the refractory or even life-threatening complications of gastroesophageal reflux (GER), including failure to thrive (FTT), recurrent aspiration pneumonia, apnea, asthma, esophagitis, bleeding, and stricture formation. Several reviews documenting the follow-up of pediatric patients after a GF have presented data without paying simultaneous attention to age at time of procedure, type of fundoplication, and concurrent medical problems. ${ }^{1-4}$ There is little published information on the natural history of the anterior (AF) and Nissen fundoplication in infants and young children.

The primary goals of operative intervention for GER are to increase the high pressure zone in the lower esophagus, to accentuate the angle of $\mathrm{His}$, and to increase the length of the intraabdominal esophagus. $^{5-7}$ Whether anatomic and mechanical changes occur with growth of the infant or young child result in reduction in the efficacy of the GF has not previously been evaluated. Therefore, this study was designed to evaluate the long-term efficacy of GF in young growing children who were less than 2 years of age at the time of operation.

\section{MATERIALS AND METHODS}

From January 1974 to June 1991, 160 children under 2 years of age (mean, $9 \pm 7$ months) were treated for GFR with Nissen or anterior fundoplications at the C.S. Mott Children's Hospital. In addition to a retrospective review of the medical records of these patients, parents were contacted for telephone interviews in October 1992. Initial presentation, concurrent medical conditions, type of GF, and results of the procedure were evaluated through clinical follow-up and by objective studies. All 160 children have had follow-up for an average of $4.2 \pm 3.7$ years (range, 1 month to 15.5 years). Ninety-six patients were available for evaluation for more than 2 years after the surgery (average, $5.3 \pm 3.0$ years; range. 2.0 to 15.5 years)

\section{Clinical Presentation}

The indications for operation were similar to those cited in other series and are demonstrated in Fig $18^{8-14}$ The most common presenting symptoms were FTT in 108 children $(68 \%)$, severe recurrent emesis in $92(58 \%)$, aspiration pneumonia in $84(53 \%)$. and apnea in $47(30 \%)$. All patients had either life-threatening GER or severe GER that did not respond to conservative medical management, which included use of small, frequent, and upright feedings with administration of melocloprantide or an $\mathrm{H} 2$ antagonist.

The patient population consisted of 100 males and 60 females; this male:female ratio is consistent with that of several other series. ${ }^{9,15.16}$ Fifty-eight patients were less than 6 months old, 57 were 6 to 12 months of age, and 45 were 12 to 24 months of age. Concurrent medical conditions were present in 124 patients ( $78 \%$ ). Seventy-four $(47 \%)$ had neurological impairment (NI), most commonly caused by anoxic encephalopathy. Twenty $(13 \%)$ had a history of esophageal atresia (EA), and $85(54 \%)$ had another significant medical disorder such as Down's syndrome. VATER association, severe cardiac anomalies, Noonan's syndrome, Möbius' syndrome, congenital diaphragmatic hernia, or prematurity.

\section{Diagnosis}

The diagnosis of GER was made by clinical history and physical examination, together with the aid of several diagnostic studies including harium swallow, $\mathrm{pH}$ probe, upper endoscopy, gastric emptying study, and/or manometry (Table 1). Barium swallow was diagnostic in 124 of 157 patients ( $79 \%$ ). The pH probe test showed GER in 98 of 100 patients ( $98 \%$ ). Sixty-eight of the 100 patients whose $\mathrm{pH}$ probe study was diagnostic also had a positive finding

From the Section of Pediatric Surgen, Mott Children's Hospital and the University of Michigan, Ann Arbor, MI.

Presented at the 26th Annual Meeting of the Pacific Association of Pediatric Surgeons, Caims, Queensland, Australia, May 9-14, 1993.

Address reprint requests to Ronald B. Hirschl, MD, L2110 Maternal and Child Health Center, 1500 E Medical Center Dr. Ann Arbor, MI $48109-0245$.

Copyright 1994 by W.B. Saunders Company

0022-3468/94/2905-0024\$03.00/0 


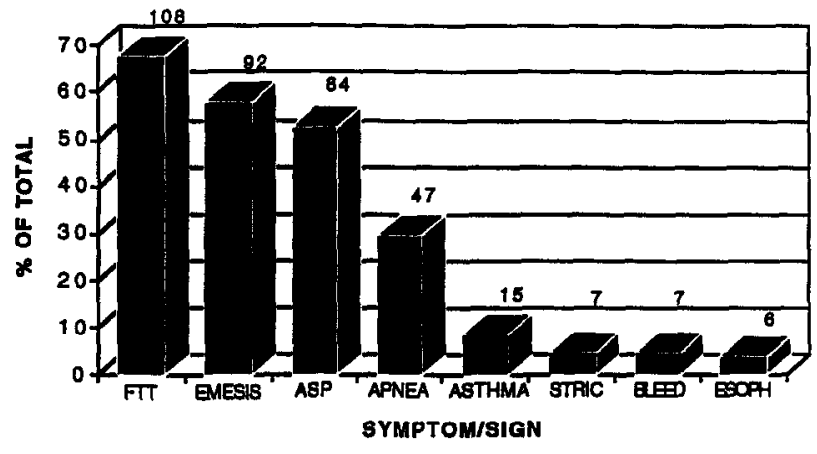

Fig 1. Clinical signs and symptoms of the patients with gastroesophageal reflux. FTT, failure to thrive; Asp, aspiration pneumonia; Strict, stricture; Bleed, bleeding; Esoph, esophagitis.

from the barium swallow. Gastric emptying studies, endoscopy, and manometry were diagnostic of GER in 22 of $32(69 \%), 16$ of 23 (70\%), and 4 of $7(57 \%)$, respectively.

\section{Procedure}

One hundred twenty-six patients $(79 \%)$ underwent Nissen fundoplication, and $33(21 \%)$ had an AF. The Nissen technique consists of performing a $360^{\circ}$ wrap of the gastric fundus around the gastroesophageal junction, together with tightening of the esophageal hiatus. ${ }^{17}$ The AF combines a partial $270^{\circ}$ wrap with a crural repair. $^{18}$

\section{RESULTS}

Of the 160 patients, $24(15 \%)$ died of unrelated causes. Ninety-six patients $(60 \%)$ were available for follow-up for more than 2 years after the surgery, and $48(30 \%)$ had follow-up of less than 2 years. Sixteen patients $(10 \%)$ were lost to follow-up. Information was available on all 160 patients for an average of $4.2 \pm 3.7$ years (range, 1 month to 15.5 years) after surgery. The average follow-up period for the 96 patients who were evaluated for more than 2 years after surgery was $5.3 \pm 3.0$ years (range, 2.0 to 15.5 years). The telephone interview process allowed classification of the patients as normal, improved, or having recurrent reflux. The improved category included patients who had relief of GER, but in whom gas bloat or abnormal eating habits developed; in addition, patients with recurrent but very mild and easily controlled GER symptoms were considered "improved." The results of the GF procedures are based on the 96 patients with follow-up of more than

Table 1. Number of Positive Results According to Test

\begin{tabular}{lcr}
\hline \multicolumn{1}{c}{ Test } & $n(\%)$ & $\begin{array}{c}\text { No. of Positive } \\
\text { Studies (\%) }\end{array}$ \\
\hline Barium swallow & $157(99 \%)$ & $124(79 \%)$ \\
pH probe & $100(63 \%)$ & $98(98 \%)$ \\
Gastric emptying study & $32(20 \%)$ & $22(69 \%)$ \\
Endoscopy & $23(13 \%)$ & $16(70 \%)$ \\
Manometry & $7(4 \%)$ & $4(57 \%)$ \\
\hline
\end{tabular}

2 years, and are stratified by age, type of GF, and the presence of concurrent medical disorders.

The long-term evaluation of these study patients is summarized in Fig 2. Overall, 69 (71\%) were normal, and $16(17 \%)$ were improved. Eleven $(12 \%)$ had recurrent reflux requiring another fundoplication. After the second procedure, 75 of the 96 patients (78\%) were normal, while $19(20 \%)$ were improved (Fig 3). Overall, $98 \%$ of patients are normal or significantly improved. Two patients continue to have recurrent severe GER with FTT, emesis, recurrent aspiration pneumonia, or esophagitis. The most frequent recurrent symptoms were emesis in $12(12 \%)$, FTT in $13(14 \%)$, and aspiration pneumonia in 17 $(18 \%)$. Clinical resolution of FTT, severe recurrent emesis, and aspiration occurred after GF in $87 \%$, $92 \%$, and $70 \%$, respectively.

Patient age at the time of operation is further subdivided as follows: less than 6 months (34 patients), 6 to 12 months ( 35 patients), and 12 to 24 months (27 patients). As seen in Fig 2, there was no difference in efficacy among the groups. A second fundoplication was necessary for $6 \%, 20 \%$, and $7 \%$, respectively. After the second procedure, $78 \%, 74 \%$, and $85 \%$ were normal, and $100 \%, 94 \%$, and $100 \%$ were normal or improved. The two children with severe recurrent GER (despite repeated procedures) account for the $6 \%$ of children aged 6 to 12 months who did not have relief of symptoms. A trend toward higher recurrence of GER was noted in the 6-to-12month age group, but this was not statistically signifcant.

As seen in Fig 4, the results were also analyzed with respect to type of GF. There was no statistical difference in outcome between the two procedures. Gas bloat syndrome was present in eight (9\%) patients after the Nissen operation, but in only two (3\%) after the AF; however, this was not statistically significant. A second procedure was required for nine (12\%) patients who had a Nissen operation and two (9\%) who had an AF. The Nissen technique was used for 10 of the 11 repeat procedurcs. One original Nissen procedure was redone using the AF tech-

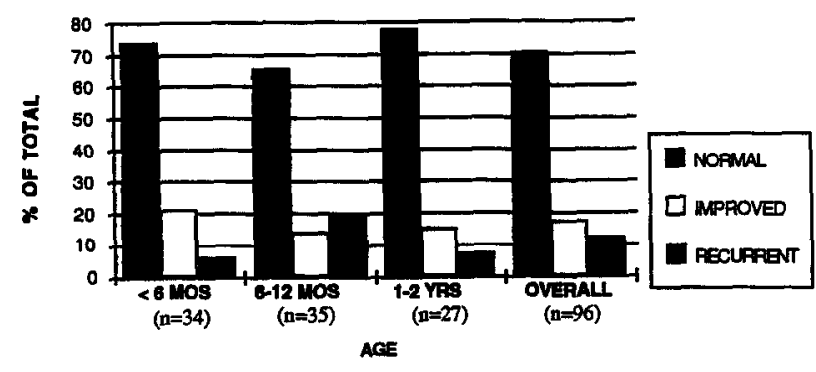

Fig 2. Results of GF by age. 


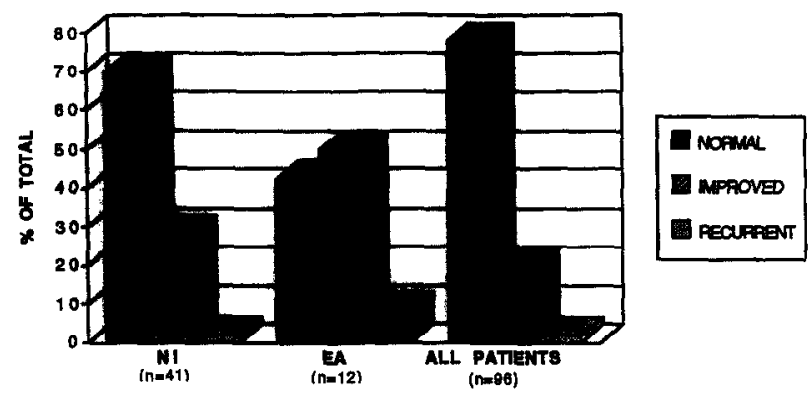

Fig 3. Results of GF after primary and, when necessary, repeat GF. NI, neurological impairment; EA, esophageal atresia.

nique. During follow-up, it was noted that five of the 10 patients undergoing Nissen redo procedures were normal, three were improved, and two had severe recurrent GER. The one patient with an $A F$ redo procedure is normal. A third fundoplication procedure was performed for the two patients in whom the Nissen procedure failed twice; these patients had recurrent GER. Both are living and are receiving treatment with antacids, ranitidine, and dietary management.

Seventy-five of the 96 patients (78\%) had concurrent medical problems. The most common disorders were NI (41 patients) and esophageal atresia (12 patients). Figure 4 shows that children with EA had a higher recurrence rate $(P=.16)$. Additional procedures were necessary for $17 \%$ of those with NI and $25 \%$ of those with EA. Including those with a redo GF, $70 \%$ of those with NI and $42 \%$ of those with EA were normal, and $28 \%$ of those with $\mathrm{NI}$ and $50 \%$ of those with EA were improved (Fig 3). Therefore, overall, the GF procedure was successful for $98 \%$ and $92 \%$ of NI and EA patients, respectively. One patient in each category currently has severe GER; these are the two patients mentioned previously.

\section{Operative Failures}

Eleven of the 96 patients required reoperation because of recurrent symptomatic reflux. In all these patients, recurrence of GER was demonstrated by return of preoperative symptoms. The average length

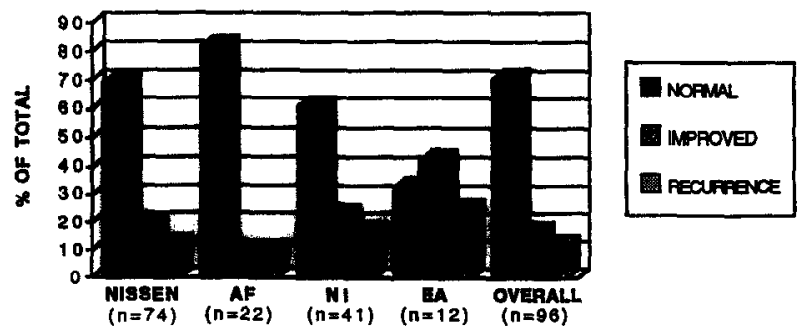

Fig 4. Results of GF in patients with the anterior (AF) or Nissen fundoplication, and in patients with neurological impairment (NI) or esophageal atresia (EA). of time between the initial procedure and the onset of recurrent GER was 11 months (range, 2 to 32 months). Seven (64\%) of the patients with recurrence had NI, and three (27\%) had EA. The remaining patient had no other concurrent medical problems. During surgery, partial breakdown of the wrap was noted in six patients, slippage of the wrap into the chest and partial breakdown of the wrap was noted in two, isolated slippage of the wrap in one, complete disruption of the wrap in two, and gastric outlet obstruction in one. Six $(55 \%)$ of these patients are now asymptomatic; three $(27 \%)$ are improved.

Two patients underwent a third GF. One of them had a perforated gastric ulcer after the second GF; a third wrap was performed at the time the ulcer was oversewn. The second patient had a gastric leak around the gastrostomy site after the second and third fundoplications. Postoperatively, Candida peritonitis developed as well as an associated intraabdominal abcess that required takedown of the GF and placement of a jejunal feeding tube.

\section{DISCUSSION}

GF is one of the most frequently performed operations in pediatric surgical centers in the United States. Outcome, morbidity, and mortality are consistently favorable, as noted in several large series. ${ }^{8-}$ $10,12,19$ However, only one study had been dedicated to children less than 12 months of age. ${ }^{8}$ Given the evolving physiology of an infant's "antireflux" mechanisms and the extensive growth that takes place after operation, one might expect the long-term efficacy of a GF procedure to differ from that in older children or adults. This study indicates that the outcome of GF is not affected by patient age at the time of the procedure.

Boix-Ochoa and Canals demonstrated gradual maturation of the lower esophageal sphincter (LES) by analyzing 4,026 manometric studies from 680 children from 1 day to 6 months of age. ${ }^{20}$ At 6 to 7 weeks, an effective LES was apparent in all patients, regardless of gestational age or weight. They subsequently recommended careful selection of patients less than 6 months old for GF because of the immaturity of their antireflux mechanisms. They considered all chronic GER after 6 months of age to be pathological. Carre observed that (1) clinical GER in infants usually develops by 6 weeks of age, (2) the majority of these patients have significant improvement without therapy, and (3) $60 \%$ are asymptomatic by 2 years of age. ${ }^{21}$ The greatest improvement was temporally related to the initiation of solids in the child's diet and to the change to upright posture between 6 and 12 months of age. Without surgery, the 
natural history includes persistent vomiting until 4 years of age in $30 \%$, a $5 \%$ mortality from pneumonia, and a $5 \%$ incidence of esophageal strictures. Based on these data, medical management is the recommended first choice of treatment for infants with GER, whereas operative therapy is indicated for persistent regurgitation with growth retardation, respiratory complications, or esophagitis. ${ }^{21,22}$

Our study evaluated the long-term outcome of operative management for GER in patients under 2 years of age, subdividing the patient population into three age groups ( $<6$ months, 6 to 12 months, $>12$ months at the time of surgery). There was no statistically significant difference in GF success between the age groups. The percentages of patients rated as normal, improved, or having recurrence are similar to those of other studies evaluating children of various ages. $^{8-10,13,14,23}$ From this study, it cannot be determined whether sustained relief of symptoms resulted from the GF itself or from spontaneous improvement. However, substantial long-term improvement or complete resolution of symptoms was observed in the majority of our patients after the GF.

The most widely used GF is the Nissen procedure, whose disadvantages include frequent inability to vomit and the development of gas-bloat syndrome. Both of these are avoided with the AF procedure; however, its long-term efficacy in the growing child had not becn cvaluated previously. From our data, there was no statistically significant difference in outcome, with respect to recurrence of reflux symptoms, between the Nissen and AF procedures. Gasbloat syndrome was more common in the Nissen group ( $9 \%$ of patients) than in the AF group (3\% of patients); however, the difference was not statistically significant.

NI and EA were the most common concurrent medical problems observed in our patients. Although the number of patients with NI who had recurrent GER is not significantly greater than the incidence of
NI in the overall population, $64 \%$ of the patients in this study who required a second GF had NI. In this group, poorly controlled seizures, constipation, delayed gastric emptying, and aerophagia contribute to an altered intrinsic gastric tone and an increase in intraabdominal pressure. ${ }^{15,24}$ These factors predispose the NI patient to GER and may also contribute to an increased incidence of GER after GF in this population. In children under 2 years of age who undergo Nissen GF at our hospital, seizure control and pulmonary toilet are optimized preoperatively, and gastrostomy tubes are routinely placed at the time of surgery to augment nutrition and to prevent gas bloating and wrap distension in the early postoperative period..$^{15}$ Presently, all NI patients are evaluated preoperatively with a gastric emptying nuclear scan. If delayed gastric emptying is documented, a pyloromyotomy or pyloroplasty is performed at the time of the GF.

Although patients with EA have decreased LES pressure (LESP), decreased LES length (LESL), and esophagogastric motor abnormalities, ${ }^{25}$ improvement in these factors has been observed after performance of an antireflux procedure. However, after GF, EA patients have lower-esophageal simultaneous dysfunctional contractions, noted by manometry, with several studies indicating that this may be congenital. ${ }^{26-31}$ Although not statistically significant, our patients with surgically corrected EA had a higher recurrence of GER after their primary GF procedure. In view of the inherent esophageal dysmotility, it is not surprising that persistent emesis, FTT, and aspiration were more common among these patients. We hypothesize that the partial AF wrap is a better option for this group because it corrects the GER while avoiding the relative GE junction obstruction of the dysmotile esophagus, which is induced by the Nissen fundoplication. ${ }^{32}$ Further experience with the partial AF wrap in patients with EA is necessary and is currently being evaluated at our institution.

\section{REFERENCES}

1. Tunnel WP, Smith EI, Carson JA: Gastroesophageal reflux in childhood. Ann Surg 197:560-565, 1983

2. Vane DW, Harmel RP Jr, King DR, et al: The effectiveness of Nissen fundoplication in neurologically impaired children with gastroesophageal reflux. Surgery 98:662-666, 1985

3. Fonkalsrud EW, Ament ME, Berquist W: Surgical management of the gastroesophageal reflux syndrome in childhood. Surgery 97:42-48, 1985

4. Dedinsky GK, Vane DW, Black CT, et al: Complications and reoperation after Nissen fundoplication in childhood. Am J Surg 153:177-183, 1987

5. Fyke FE, Code CF, Schlegel JF: The gastroesophageal sphincter in healthy human beings. Gastroenterologia 86:135-150, 1956

6. Liebermann D, Allgower M, Schmid P, et al: Muscular equivalent of the lower esophageal sphincter. Gastroenterology 76:31-38, 1979

7. Bombeck CT, Dillard DH, Nyhus LM: Muscular anatomy of the gastroesophageal junction and role of phrenoesophageal competence. Ann Surg 164:643-652, 1966

8. Randolph J: Experience with the Nissen fundoplication for correction of gastroesophageal reflux in infants. Ann Surg 198:579584,1983

9. Fung KP, Seagram G, Pasieka $J$, et al: Investigation and outcome of 121 infants and children requiring Nissen fundoplication for the management of gastroesophageal reflux. Clin Invest Med 13:237-246, 1990

10. Ashcraft KW, Holder TM, Amoury TA, et al: The Thal fundoplication for gastroesophageal reflux. J Pediatr Surg 19:480483,1984 
11. Opie JC, Chaye H, Fraser GC: Fundoplication and pediatric esophageal manometry: Actuarial analysis over 7 years. I Pediatr Surg 22:935-938, 1987

12. Leape LL, Ramenofsky ML: Surgical treatment of gastroesophageal reflux in children. Am J Dis Child 134:935-938, 1980

13. Foglia RP, Fonkalsrud EW, Ament ME, et al: Gastroesophageal fundoplication for the management of chronic pulmonary disease in children. Am J Surg 140:72-79, 1980

14. Spitz L, Kirtane J: Results and complications of surgery for gastroesophageal reflux. Arch Dis Child 60:743-747, 1985

15. Wheatley MJ, Coran AG, Wesley JR, et al: Redo fundoplication in infants and children with recurrent gastrocsophageal reflux. J Pediatr Surg 26:758-761, 1991

16. Skinner DB, Belsey RHR, Hendrix TR, et al: Gastroesophageal Reflux and Hiatal Hernia. Boston, MA, Little, Brown 1972. p 143

17. Nissen R: Gustropexy and fundoplication in surgical treatment of hiatus hernia. Am J Dig Dis 6:954-961, 1961

18. Ashcraft KW, Goodwin CD. Amoury RA, et al: The Thal fundoplication. J Pediatr Surg 13:643-647, 1978

19. Hansberger JK, Corey JJ, Johnson DG, et al: Long-term follow-up of surgery for gastroesophageal reflux in infants and children. J Pediatr 102:505-508, 1983

20. Boix-Ochoa J, Canals J: Maturation of the lower esophageal sphincter. J Pediatr Surg 11:749-756, 1976

21. Carre IJ: The natural history of the partial thoracic stomach (hiatus hernia) in children. Arch Dis Child 34:344-353, 1959

22. Carre IJ: Postural treatment of children with partial thoracic stomach (hiatus hernia). Arch Dis Child 35:569-580, 1960
23. Boix-Ochoa J: Diagnosis and management of gastroesophageal reflux in children. Surg Annu 13:123-128, 1981

24. Wesley JR, Coran AG, Sarahan TM, et al: The need for evaluation of gastroesophageal reflux in brain-damaged children referred for feeding gastrostomy. J Pediatr Surg 16:866-87I, 1981

25. Takano K. Iwafuchi M, Uchiyama M, et al: Evaluation of lower esophageal sphincter function in infants and children following esophageal surgery. J Pediatr Surg 23:410-414, 1988

26. Romeo G, Zuccarello B. Proietto F, et al: Disorders of the esophageal motor activity in atresia of the esophagus. J Pediatr Surg 22:120-124, 1987

27. Lind JF, Blanchard RJ, Guyda H: Esophageal motility in tracheoesophageal fistula and esophageal atresia. Surg Gynecol Obstet 123:557-564, 1966

28. Duranceau A, Fisher SR, Flye MW, et al: Motor function of the esophagus after repair of esophageal atresia and tracheoesophageal fistula. Surgery 82:116-123, 1977

29. Parker AF, Christie DL, Cahill JL, et al: Incidence and significance of gastroesophageal reflux following repair of esophageal atresia and tracheoesophageal fistula and the need for antirefiux procedures. J Pediatr Surg 14:5-8, 1979

30. Shepard R, Fenn S, Sieber WK: Evaluation of esophageal function in postoperative esophageal atresia and tracheoesophageal fistula. Surgery 59:608-617, 1966

31. Orringer MB, Kirsh MM, Sloan H, et al: Long-term esophageal function following repair of esophageal atresia. Ann Surg 186:436-443, 1977

32. Wheatley MJ, Coran AG, Wesley JR: Efficacy of the Nissen fundoplication in the management of gastroesophageal refiux following esophageal atresia repair. J Pediatr Surg 28:53-55, 1993 